\title{
VIII edición de Actualízate: La profesión a través del espejo
}

CARMEN MORALES

Junta Directiva Sedic -Vocalía de Publicaciones

SEDIC ha celebrado la VIII edición de la Jornada Actualízate, bajo el título La profesión a través del Espejo. Profesionales de la gestión de la información y la documentación han analizado la epistemología de la documentación, los nuevos estudios y perfiles.

SEDIC, Actualízate, Gestión de la Información, Documentación, Epistemología, Nuevos perfiles

\section{Crónica de la VIII edición de Actualízate: La profesión a través del espejo}

SEDIC celebró el pasado 11 de mayo la octava edición de Actualízate, una iniciativa nacida en 2014 y desarrollada en colaboración con el Departamento de Biblioteconomía y Documentación de la Universidad Complutense de Madrid (UCM), que tiene por objetivo poner en contacto el ámbito de la empresa y la Universidad. Para ello, cada año se organiza una jornada profesional en la que empresas e instituciones relacionadas con la gestión de la información y/o la gestión documental dan a conocer sus proyectos más innovadores, favoreciéndose, de este modo, la creación de sinergias entre la actividad profesional y el ámbito universitario.

La inauguración de la octava edición de Actualízate, que este año se ha celebrado bajo el lema La profesión a través del espejo, corrió cargo de Isabel Villaseñor, directora del Departamento de Biblioteconomía y Documentación de la Facultad de Ciencias de la Documentación de la UCM, y Blanca San José Montano, miembro de la Junta Directiva de SEDIC. En el transcurso de la inauguración se destacó cómo, a lo largo de estos años, se ha puesto de manifiesto que son muchas las sinergias que unen los ámbitos empresarial y universitario. Buen ejemplo de ello es el Premio al proyecto universitario más innovador en el ámbito de la gestión de la información y la documentación que SEDIC convoca cada año con objeto de destacar públicamente los proyectos teóricos más innovadores que pudieran tener mayor aplicación práctica en el ámbito empresarial entre los trabajos de los estudiantes universitarios de universidades españolas (Trabajo Final de Máster o Trabajo Final de Grado). El plazo para la presentación de trabajos que puedan optar al galardón está abierto hasta el próximo 31 de octubre.

La primera sesión, Epistemología de la documentación, contó con la participación de Lluís Anglada, director de Ciencia abierta del CSUC (Consorci de Serveis Universitaris de Catalunya) y 
José Antonio Magán, bibliotecario en la UCM, bajo la moderación por José Luis Lopez Yepes, Catedrático emérito en la Facultad de Ciencias de la Documentación de la UCM.

José Luis Lopez Yepes, tras recordar a Emilia Currás, una figura destacable del sector, recientemente fallecida, entró en el tema de la mesa en la que anunció que se abordarían temas tales como la historia de la profesión, la valoración social de la misma, la evolución de los diferentes perfiles, la forma en la que la pandemia ha afectado al sector y la visión a largo plazo sobre la formación universitaria.

Tras esta breve introducción, Lluís Anglada destacó la importancia de una visión global de la profesión, una profesión única, que engloba a bibliotecarios, archiveros, museólogos y documentalistas en sus más amplias variedades, incidiendo en cómo siempre ha existido un debate, que ha consumido innumerables esfuerzos favoreciendo distancias entre sus profesionales, acerca de qué nombre debería realmente recibir la profesión.

En su opinión hay diferentes factores que han colocado la profesión en el punto en el que está actualmente: ausencia de estudios de prestigio, la fragmentación profesional o la incapacidad del sector de encontrar una voz propia.

Anglada cerró su intervención destacando que "en estos momentos, el viento sopla a nuestro favor. Se habla en todos los ámbitos de información, hay éxitos de gestión en España, pero también hay debilidades que creo que son a las que hay que hacer frente".

Por su parte José Antonio Magán inicio su intervención destacando que "las bibliotecas son tradicionalmente un sector enfermo. Siempre han sido makerspace, pero es ahora cuando empieza a acuñarse y a aplicarse este concepto. Siempre ha habido recursos, los usuarios lo saben, pero, tal vez, los propios bibliotecarios no hemos sabido transmitir este concepto".

Magán destacó la necesidad de que el bibliotecario cuente con una amplia formación y cultura para posicionarse entre los libros y los usuarios: "Para orientar al lector hay que tener un gran bagaje cultural no solo una técnica. La parte técnica recaerá en empresas y los bibliotecarios deberán asesorar", precisó.

En relación a la forma en la que la pandemia ha afectado al sector, destacó que esta experiencia ha ayudado a los bibliotecarios a reconocer que no todas las actividades y actuaciones deben ser presenciales e incidió en cómo, por ejemplo, la puesta en marcha de talleres online ha conseguido hasta 250 asistentes frente a los catorce o quince que idénticas iniciativas en modo presencial tenían antes. Aun así, concretó que, si bien se debe trabajar de otra manera, la biblioteca debe permanecer abierta. "Hay buenas instalaciones y están llenas porque la gente quiere relacionarse, pero también desean estar solos en público, más que estar solos en casa, y eso es algo que las bibliotecas pueden ofrecer", concluyó.

Magán cerró su intervención destacando la relevancia que los expertos en metadatos, en desarrollo de colecciones, en fondos temáticos, en fondo antiguo, en gestión de colecciones digitales, en bibliometría o en minería de datos adquirirán en los próximos años.

La segunda sesión, Nuevos estudios para nuevos perfiles, fue moderada por Elisa GarcíaMorales, directora de Inforarea S. L., y contó con la participación de José Antonio Gómez, profesor de Documentación de la Universidad de Murcia, Ernest Abadal, Catedrático de la Facultat de Información y Medios Audiovisuales y Vicerrector de Personal Docente e Investigador. Universitat de Barcelona, y Pablo Parra, profesor Ayudante- Doctor en la Facultad de Ciencias de la Documentación de la UCM.

Antes de dar paso a los ponentes, Elisa García-Morales recordó el programa de Mentoría de SEDIC y animó a los profesionales a participar. Esta iniciativa permite a aquellos más jóvenes 
analizar sus objetivos profesionales y reconducir los mismos bajo el asesoramiento de sus mentores.

José Antonio Gómez inició su intervención destacando como el mundo universitario no ha terminado de adaptarse a los nuevos requerimientos de la profesión. Recordó como cuando esta disciplina nació a principios de los años ochenta lo hizo con carácter generalista que veía al profesional como algo unitario, con formación técnica para trabajar en archivos, bibliotecas y documentación. Eran estudios amplios, que luego podrían haberse completado con especialización a nivel máster, pero no se hizo, y así fue como se desarrolló la formación universitaria durante veinte años. Tras esta etapa se ha evolucionado hacia una formación más concreta, las ciencias de la documentación y contenidos digitales, que, a día de hoy, se corresponde con la realidad, pero, que, según Gómez, "ha de completarse con másteres que deben hacerse en colaboración con las asociaciones profesionales".

José Antonio Gómez cerró su intervención destacando que hay buenas expectativas para los profesionales del sector, siempre que los estudios sepan responder a las expectativas del mercado. Por último, destacó que "asociaciones y universidad deben luchar juntos contra la precariedad laboral del sector, algo que desanima a los estudiantes, que acaban dejando estos estudios en favor de otras alternativas".

Ernest Abadal inició su intervención centrándose en cómo han evolucionado los perfiles profesionales y en cómo los másteres actuales están dando respuesta a los tres tipos de perfiles que hay: documentación, bibliotecas y archivos. Aun así, insistió en que hay que reorientar los estudios, de modo que atiendan a las necesidades actuales: "Se está renovando el grado y creo que esta renovación es positiva; se está apostando por los másteres que se pueden adaptar mejor a demandas cambiantes ya que el grado tiene un proceso más lento; la biblioteconomía y la documentación está presente en otros grados y hay que mantenerlo (periodismo y comunicación audiovisual, por ejemplo), de modo que la profesión forme parte de dobles grados y atraigamos más estudiantes".

En cuanto a la forma en la que el COVID ha influido en el entorno bibliotecario, tan centrado en servicios presenciales, destacó que se ha comprobado que hay gran parte del trabajo que puede realizarse a distancia.

Por último, Pablo Parra arrancó su participación aludiendo a la falta de reconocimiento de la profesión, a unas líneas de estudio no siempre acertadas y a unas políticas ministeriales que no han ayudado al sector, pero puso el foco en el componente vocacional: "Muchos estudiantes llegan a este grado de rebote, hasta dos terceras partes habría preferido estudiar otra profesión, y por eso hay cierto abandono de la carrera. Actualmente, los estudios son insatisfactorios y para planificar una formación académica adecuada sería necesario conocer bien el perfil del alumno que se matricula en estos estudios".

En lo que al COVID se refiere, Parra apuntó que se aprecia cierto pesimismo en los estudiantes sobre su futuro laboral, así como una importante tendencia entre los mismos a querer trabajar en la empresa pública, para lo que consideran que la formación universitaria puede ser de más ayuda que la ofrecida en academias.

Parra cerró su intervención destacando, por una parte. la importancia que las ciencias de datos y los laboratorios urbanos va na a tener en un futuro próximo, y, por otra, en la necesidad de que las asociaciones profesionales retomen el Grupo de Perfiles Profesionales del Ministerio, recientemente desaparecido.

Isabel Villaseñor y Carmen Morales Sanabria, miembro de la Junta Directiva de SEDIC, fueron las encargadas de cerrar la jornada. 
Sobre el autor

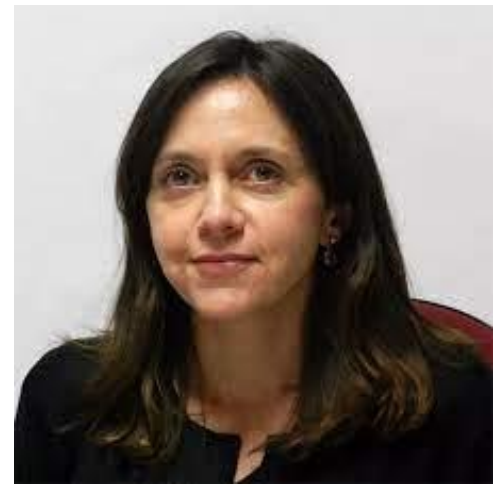

CARMEN MORALES

Junta Directiva Sedic - Vocalía de Publicaciones

Licenciada en Ciencias de la Información, rama Periodismo, por la Universidad Complutense de Madrid y funcionaria de carrera del Cuerpo de Técnicos Superiores Facultativos de Archivos, Bibliotecas y Museos, Especialidad Bibliotecas, de la Comunidad de Madrid. En la actualidad, es técnico de apoyo en la Dirección General de Comercio y Consumo:

- https://www.linkedin.com/in/m\%C2\%AA-del-carmenmorales-sanabria-1a8aa71a/?originalSubdomain=es 